

\title{
Thyroxine downregulates Sox9 and promotes chondrocyte hypertrophy ${ }^{\text {th }}$, 败猔
}

\author{
Yasunori Okubo and A. Hari Reddi* \\ Center for Tissue Regeneration and Repair, Department of Orthopaedic Surgery, School of Medicine, University of California, \\ Davis, Sacramento, CA 95817, USA
}

Received 17 April 2003

\begin{abstract}
Thyroid hormones exert a profound effect on development, growth, and metabolism of skeleton. In the present study, we evaluated the effects of thyroxine (T4) and growth hormone $(\mathrm{GH})$ on the terminal differentiation of rib growth plate chondrocytes in three-dimensional pellet culture. T4 $(30 \mathrm{ng} / \mathrm{ml})$ stimulated the expressions of type II and X collagens, alkaline phosphatase (ALP) activity. On the other hand, the expression of chondrogenic transcription factor Sox 9 in the T4 treatment group decreased significantly compared to the control group. T4 downregulates Sox 9 and promotes hypertrophy. After day 7, T4 increases dramatically the synthesis of type X collagen mRNA, ALP activity, and cellular hypertrophy. Addition of GH does not modify the action of T4. Thus, T4 acts directly on chondrocytes. In conclusion, we demonstrated that T4 enhances the cellular and molecular events of terminal differentiation and hypertrophy of chondrocytes in the three-dimensional cultures.
\end{abstract}

(c) 2003 Elsevier Science (USA). All rights reserved.

Keywords: Terminal differentiation; Hypertrophy; Three-dimensional culture; Thyroxine; Sox9

The differentiation of mesenchymal cells into chondrocytes occurs by a multistep pathway, accompanied by expression of cartilage specific gene producing extracellular matrix proteins, and maturation of prechondrocytic cells into hypertrophic chondrocytes [1]. The factors that regulate this process include morphogenetic proteins, growth and differentiation factors, extracellular matrix proteins, and specific transcription factors. In the epiphyseal growth plate of developing skeleton, round progenitors, flattened chondrocytes proliferate unidirectionally with stacks of polarized cells. After these cells cease proliferating, their differentiation program changes and they become hypertrophic chondrocytes with increased volume. The most distal hypertrophic chondrocytes acquire the ability to mineralize their extracellular matrix before they undergo

\footnotetext{
This research was supported by a grant from the Shriners Hospital for Children.

出诂 Abbreviations: ALP, alkaline phosphatase; GAPDH, glyceraldehyde phosphate dehydrogenase.

${ }^{*}$ Corresponding author. Fax: 1-916-734-5750.

E-mail address: ahreddi@ucdavis.edu (A.H. Reddi).
}

apoptosis and are replaced by bone. This terminal hypertrophy and differentiation process is marked by an increase in cell volume, synthesis of type X collagen, and increased levels of alkaline phosphatase (ALP) activity [2].

Thyroid hormones are important regulators of endochondral ossification [3,4]. The two main thyroid hormones in the human are triiodothyronine (T3) or thyroxine (T4). Disturbances of thyroid function are among the most common causes of skeletal abnormalities including growth. Thyroid hormones stimulated the cartilage growth, especially the terminal differentiation of hypertrophy. T4 is the major secretory product from the thyroid gland. T4 was previously reported to have effects on growth plate $[5,6]$ and its activity was as equal as T3 [7]. Growth hormone ( $\mathrm{GH})$ has direct effects on the growth plate to stimulate longitudinal growth, but it is not clear as to how it synergizes with T4 in skeletal growth. In the present study, we have evaluated the effects of T4 and GH in pellet culture of rib growth plate chondrocytes. Since these culture systems mimic in vivo cartilage differentiation, they provide a useful system to elucidate the molecular controls 
governing the chondrogenic developmental pathway $[6,8,9]$.

\section{Materials and methods}

Cell culture. Chondrocytes were prepared from the ventral parts of rib cartilage of 2-4 days old C57BL/6 mice (Charles River, Boston, MA) [10]. The rib costal cages were rinsed with PBS, placed into $0.25 \%$ trypsin, and incubated at $37^{\circ} \mathrm{C}$ for $20 \mathrm{~min}$ with intermittent vortexing to loosen the connective tissues. Cartilages were then treated with $3 \mathrm{mg} / \mathrm{ml}$ collagenase P (Roche Applied Science, Indianapolis, IN) in DMEM (Gibco-BRL Life Technologies, Grand Island, NY) containing $5 \%$ heat-inactivated fetal bovine serum (FBS; Gibco) for $30 \mathrm{~min}$ at $37^{\circ} \mathrm{C}$. They are rinsed with PBS and then digested with $3 \mathrm{mg} / \mathrm{ml}$ collagenase $\mathrm{P}$ for $3 \mathrm{~h}$ in a shaking water bath at $37^{\circ} \mathrm{C}$. Released chondrocytes were passed through a 70- $\mu \mathrm{m}$ nylon mesh (Falcon, Bedford, MA), washed using PBS, and the cells recovered by centrifugation at $1000 \mathrm{rpm}$ for $5 \mathrm{~min}$ at room temperature and resuspended in DMEM/ F12.

Three-dimensional pellet culture. Chondrocytes were cultured as three-dimensional cell pellets as previously described [6]. Briefly, $1 \mathrm{ml}$ aliquots containing $1.6 \times 10^{5}$ cells each were added to $15 \mathrm{ml}$ conical polypropylene centrifuge tubes (Falcon) and the cells pelleted by centrifugation at $600 \mathrm{rpm}$ for $5 \mathrm{~min}$ at room temperature. The cultures were maintained at $37^{\circ} \mathrm{C}$ in $5 \% \mathrm{CO}_{2}$ in humidified incubator. Pellets were maintained up to 21 days in DMEM/F12 supplemented with $50 \mu \mathrm{g} / \mathrm{ml}$ ascorbate phosphate (Sigma, St. Louis, MO), $100 \mu \mathrm{g} / \mathrm{ml}$ pyruvate, $1 \%$ penicillin/streptomycin (Gibco), and $50 \mathrm{mg} / \mathrm{ml} \mathrm{ITS} \mathrm{+} \mathrm{Pre-}$ mix (Becton-Dickinson, Bedford, MA; a final concentration of $6.25 \mu \mathrm{g} / \mathrm{ml}$ bovine insulin, $6.25 \mu \mathrm{g} / \mathrm{ml}$ transferrin, $6.25 \mathrm{ng} / \mathrm{ml}$ selenous acid, $1.25 \mathrm{mg} / \mathrm{ml}$ bovine serum albumin, and $5.35 \mu \mathrm{g} / \mathrm{ml}$ linoleic acid). The following factors were added to chemical defined media for 21 days culture period: L-T4 (Sigma; $30 \mathrm{ng} / \mathrm{ml}$ ) and $200 \mathrm{ng} / \mathrm{ml} \mathrm{GH} \mathrm{(Cal-}$ biochem, La Jolla, CA). Medium was changed every three days and these factors were re-added with each change of culture medium.

Tissue morphology. Pellets were fixed with $1 \%$ cetylpyridinium chloride in $10 \%$ formalin (Sigma), and embedded in paraffin, cut into 7- $\mu \mathrm{m}$ sections, and stained with toluidine blue for light microscopy.

Alkaline phosphatase activity. Cartilage pellet cultures were homogenized in $1 \mathrm{ml}$ of ice-cold $0.15 \mathrm{M} \mathrm{NaCl}$ containing $3 \mathrm{mM} \mathrm{NaHCO}_{3}$ $(\mathrm{pH}$ 7.4) with a Polytron homogenizer and centrifuged at $14,000 \mathrm{rpm}$ for $30 \mathrm{~min}$ at $4{ }^{\circ} \mathrm{C}$. The supernatants were assayed for ALP activity in $0.1 \mathrm{M}$ sodium barbital buffer ( $\mathrm{pH}$ 9.3) using $p$-nitrophenyl phosphate as a substrate as previously described [11]. The protein content was determined using BCA Kit (Pierce Chemical, Rockford, IL) using BSA as the standard. The enzyme activity expressed as units of ALP activity per mg protein.

$R N A$ isolation and quantitative RT-PCR. RNA was isolated from pellets using RNeasy Kit (Qiagen, Valencia, CA). To ensure the complete removal of DNA, we included a 15 min DNase I (Qiagen) treatment prior to the wash step of the isolation. Quantitative RT-PCR (Taqman, Applied BioSystems, Foster City, CA) was used to determine expression levels of type II collagen, type X collagen, and Sox 9 in the samples. Oligonucleotide primers and a reporter probe corresponding to cDNA sequences for type II collagen (primer 1: TGAA GACCCAGACTGCCTCAA; primer 2: CGAGGTCAGCTGGGC AGAT; probe: CGAGATCCCCTTCGGAGAGTGCTGTC), type X collagen (primer 1: AGAACGGCACGCCTACGAT; primer 2: CCA TGATTGCACTCCCTGAA; probe: CCAGGTAGCCTTTGCTGT ACTCATCATACGTGTA), and Sox9 (primer 1: TTCCGCGAC GTGGACAT; primer 2: GGTGGCAAGTATTGGTCAAACTC; probe: AGCAGCGACGTCATCTCCAACATTGA) were designed using Primer Express software (Applied BioSystems). Glyceraldehyde phosphate dehydrogenase (GAPDH) primers and probe (Applied BioSystems) were used as a control amount of RNA in each sample.
Quantitative RT-PCR was performed using Taqman EZ RT-PCR core kit and the ABI Prism 7700 sequence detector (Applied Biosystems). Thermal cycling conditions were $2 \mathrm{~min}$ at $50^{\circ} \mathrm{C}, 30 \mathrm{~min}$ at $60^{\circ} \mathrm{C}, 5 \mathrm{~min}$ at $95^{\circ} \mathrm{C}$ and 40 cycles of $20 \mathrm{~s}$ at $94^{\circ} \mathrm{C}$ and $1 \mathrm{~min}$ at $62^{\circ} \mathrm{C}$. Each sample was analyzed in triplicate. The average CT value of each sample (CT value represents the cycle at which a statistically significant increase in signal magnitude, i.e., amplified PCR product, is detected) was compared between experimental groups, and the results were documented as fold differences in expression level of type II, X collagen, and Sox9.

Statistical analysis. Data are presented as means \pm SEM. Statistical differences were performed using ANOVA with Fisher least significant difference method where appropriate. $P$ values of less than 0.05 were considered statistically significant.

\section{Results and discussion}

\section{Time course terminal differentiation of growth plate chondrocytes}

In pellet cultures of control group on day 7 , spherical cells (chondrocytes) appeared near the surface of the pellet (Fig. 1A). The chondrocytes were surrounded by cartilage characteristic proteoglycan that stained metachromatically with toluidine blue. Some hypertrophic chondrocytes were observed in the periphery of pellet. On day 14, the toluidine blue stained cartilage proteoglycan and the number of hypertrophic chondrocytes increased (Fig. 1E). However, hypertrophic chondrocytes were observed only in the periphery of pellet. There was a remarkable increase in pellet size on day 21 compared to day 7. The number of hypertrophy chondrocytes also increased (Fig. 1I). The lack of cellar hypertrophy and random orientation of the cells was noted at the center of the pellet. The expression of type X collagen and ALP activity increased significantly $(P<0.05$, day 7 ; Figs. $2 \mathrm{C}$ and $\mathrm{D})$. However, the expressions of Sox 9 and type II collagen did not significantly increase or decrease between day 7 and day 21 .

\section{T4 stimulates terminal differentiation}

The presence of $\mathrm{T} 4$ enhanced the toluidine blue staining cartilage proteoglycan and the number of hypertrophic chondrocytes from day 7 (Figs. 1C and D). The pellet size is bigger than that in the control group. There were no significant differences of the expressions of type II and X collagens and ALP activity $(P>0.05$; Figs. 2B-D). However, the expression of Sox 9 was inhibited compared to the control group $(P<0.001$; Fig. $2 \mathrm{~A})$. On day 14 , the number of hypertrophy chondrocytes and cartilage proteoglycan remarkably increased (Figs. $1 \mathrm{G}$ and $\mathrm{H}$ ). In several areas, chondrocytes became organized in a column pattern. This columnar architecture remarkably resembled the appearance of developing growth plate chondrocytes in vivo. T4 increased the expression of type X collagen, ALP activity, and pellet size significantly compared to the control group 
A



$\mathbf{E}$



I



B



F



$\mathbf{J}$



C



G



$\mathbf{K}$



D

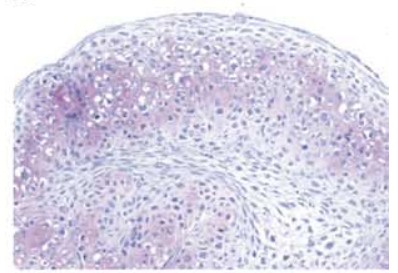

H



$\mathbf{L}$



Fig. 1. Histologic appearance of pellet cultures on days 7 (A-D), 14 (E-H), and 21 (I-L). The treatment of $200 \mathrm{ng} / \mathrm{ml}$ of GH (B,F,J), $30 \mathrm{ng} / \mathrm{ml}$ of T4 $(\mathrm{C}, \mathrm{G}, \mathrm{K}), 200 \mathrm{ng} / \mathrm{ml}$ of $\mathrm{GH}$, and $30 \mathrm{ng} / \mathrm{ml}$ of T4 (D,H,L) or no treatment (A,E,I). Toluidine blue staining. Bar, $200 \mu \mathrm{m}$. Note the hypertrophy of chondrocytes in groups treated with $\mathrm{T} 4$.

$(P<0.001$; Figs. $2 \mathrm{C}$ and D). Also on day 21 , T4 displayed consistent morphologic evidence of cellular hypertrophy (Figs. $1 \mathrm{~K}$ and L) and enhanced the size and weight of pellet. Within the T4 treatment group, the expression of type X collagen and ALP activity increased with time, however, the expression of the type II collagen and Sox9 did not alter significantly by day 21 $(P>0.05)$.

When GH was added to T4 culture, there were no differences as assessed histologically and biochemically.

\section{GH and terminal differentiation}

The histological findings in the GH treatment group were similar to those in the control group (Figs. 1B, F, and $\mathbf{J}$ ). The number of hypertrophic chondrocytes and cartilage proteoglycan increased with time. Even on day 21 , however, lack of cellar hypertrophy and random orientation of the cells was noted at the center of the pellet. Growth hormone treatment did not result in a noticeable increase in expressions of Sox9, type II collagen, type $\mathrm{X}$ collagen, ALP activity, and pellet size compared to the control group ( $P>0.05$; Figs. $2 \mathrm{~A}-\mathrm{D})$.

In the formation of cartilage, mesenchymal cells proceed through at least three distinct phases, prechondrogenic phase, proliferation, and the terminal hypertrophy and calcification phases. The organization of proliferating chondrocytes into longitudinal columns is a critical event during the development and growth of the skeleton. It is well known that growth hormone is of paramount importance in the regulation of skeletal growth and maturation [12], therefore we initially examined the effect of growth hormone on chondrocyte hypertrophy. The results revealed that growth hormone did not affect the chondrocyte hypertrophy. Because T4 is known to have synergistic effects with growth hormone during endochondral ossification $[11,13]$ and was shown to stimulate type $\mathrm{X}$ collagen synthesis and ALP activity in chondrocytes $[6,14,15]$, we investigated the effects of T4 in chemically defined media. At day 7, T4 did not affect the expressions of type II and X collagens, ALP activity, and histological findings. However, the expression of Sox9 in the T4 treatment group, which encodes a transcription factor known to regulate expression of genes encoding chondrocyte specific extracellular matrix proteins, such as type II collagen and aggrecan [16], decreased significantly compared to the control group. Sox9 is expressed in all chondroprogenitors and all differentiated chondrocytes, but not in hypertrophic chondrocytes [17,18]. Recently, it was reported that Sox 9 prevented transition of proliferating chondrocytes to hypertrophy [19]. T4 downregulates Sox 9 and promotes hypertrophy. And our results are consistent with this. 



Fig. 2. The results of quantitative RT-PCR and ALP activity on days 7,14 , and 21. Gene expression levels were normalized with respect to endogenous GAPDH. Data are means \pm SEM of three independent measurements. (A) Sox9, (B) type II collagen, (C) type X collagen, and (D) ALP activity.

Thyroid hormone has long been known to exert a profound effect on development, growth, and metabolism of skeleton [20]. T4 is the major secretory product from the thyroid gland. T4 is a prohormone and is converted to T3, the active form of thyroid hormone by $5^{\prime}$-monodeiodination in peripheral target tissue for its hormonal activity [21,22]. In previous reports using monolayer culture, T4 treatment increased type $\mathrm{X}$ collagen and ALP mRNA expressions, but did not influence the mRNA level of type II collagen [7]. In the present experiments, after day 7, T4 increases dramatically the synthesis of type X collagen mRNA, ALP activity, and cellular hypertrophy, all makers of the terminal differentiation of the growth plate chondrocytes. Chondrocytes were organized into columns when treated with T4. The cellular and molecular mechanisms by which chondrocytes form these longitudinal columns of cells are not known. It is likely to be related to interactions between the chondrocyte cytoskeleton and the surrounding extracellular matrix proteins [23]. In conclusion, T4 in chemically defined media enhances the cellular and molecular events of terminal chondrocyte differentiation in the three-dimensional pellet cultures. Thus, T4 is able to act directly on growth plate chondrocytes through GH-independent mechanism.

\section{References}

[1] A. Erlebacher, E. Filvaroff, S.E. Gitelman, R. Derynck, Toward a molecular understanding of skeletal development, Cell 80 (1995) 271-278.

[2] A.R. Poole, The growth plate: cellular physiology, cartilage assembly, and mineralization, in: B.K. Hall (Ed.), Cartilage: Molecular Aspects, Academic Press, San Diego, CA, 1992, pp. 179-211.

[3] P.H. Stern, Thyroid hormone and bone, in: D.T. Raisz, G.A. Rodan (Eds.), Principles of Bone Biology, Academic Press, San Diego, CA, 1996, pp. 521-531.

[4] D.T. Baran, The skeletal system in hypothyroidism, in: L.E. Braverman, R.D. Utiger (Eds.), The Thyroid, Williams \& Wilkins, Philadelphia, PA, 2000, pp. 828-832.

[5] R. Wakita, T. Izumi, M. Itoman, Thyroid hormone-induced chondrocyte terminal differentiation in rat femur organ culture, Cell Tissue Res. 293 (1998) 357-364.

[6] R.T. Ballock, A.H. Reddi, Thyroxine is the serum factor that regulates morphogenesis of columnar cartilage from isolated chondrocytes in chemically defined medium, J. Cell Biol. 126 (1994) 1311-1318.

[7] M. Miura, K. Tanaka, Y. Komatsu, M. Suda, A. Yasoda, Y. Sakuma, A. Ozasa, K. Nakao, Thyroid hormones promote chondrocyte differentiation in mouse ATDC5 cells and stimulate endochondral ossification in fetal mouse tibias through iodothyronine deiodinase in the growth plate, J. Bone Miner. Res. 17 (2002) 443-454.

[8] Y. Kato, M. Iwamoto, T. Koike, F. Suzuki, Y. Takano, Terminal differentiation and calcification in rabbit chondrocyte cultures grown in centrifuge tubes: regulation by transforming growth factor beta and serum factors, Proc. Natl. Acad. Sci. USA 85 (1988) 9552-9556.

[9] A.E. Denker, A.R. Haas, S.B. Nicoll, R.S. Tuan, Chondrogenic differentiation of murine C3H10T1/2 multipotential mesenchymal cells: I. Stimulation by bone morphogenetic protein-2 in highdensity micromass cultures, Differentiation 64 (1999) 67-76.

[10] V. Lefebvre, S. Garofalo, G. Zhou, M. Metsaranta, E. Vuorio, B. De Crombrugghe, Characterization of primary cultures of chondrocytes from type II collagen/beta-galactosidase transgenic mice, Matrix Biol. 14 (1994) 329-335.

[11] A.H. Reddi, N.E. Sullivan, Matrix-induced endochondral bone differentiation: influence of hypophysectomy, growth hormone, 
and thyroid-stimulating hormone, Endocrinology 107 (1980) 1291-1299.

[12] C.H. Li, H.M. Evans, M.E. Simpson, Isolation and properties of anterior hypophyseal growth hormone, J. Biol. Chem. 159 (1945) 353-366.

[13] R.D. Ray, C.W. Asling, D.G. Walker, M.F. Simpson, C.H. Li, H.M. Evans, Growth and differentiation of skeleton in thyroidectomized-hypophysectomized rats treated with thyroxine, growth hormone, and the combination, J. Bone Joint Surg. Am. 36A (1954) 94-103.

[14] K. Bohme, M. Conscience-Egli, T. Tschan, K.H. Winterhalter, P. Bruckner, Induction of proliferation or hypertrophy of chondrocytes in serum-free culture: the role of insulin-like growth factor-I, insulin, or thyroxine, J. Cell Biol. 116 (1992) 1035-1042.

[15] R. Quarto, G. Campanile, R. Cancedda, B. Dozin, Thyroid hormone, insulin, and glucocorticoids are sufficient to support chondrocyte differentiation to hypertrophy: a serum-free analysis, J. Cell Biol. 119 (1992) 989-995.

[16] V. Lefebvre, W. Huang, V.R. Harley, P.N. Goodfellow, B. de Crombrugghe, Sox 9 is a potent activator of the chondrocytespecific enhancer of the proalpha1(II) collagen gene, Mol. Cell. Biol. 17 (1997) 2336-2346.

[17] L.J. Ng, S. Wheatley, G.E. Muscat, J. Conway-Campbell, J.E. Bowles, D.M. Bell, P.P. Tam, K.S. Cheah, P. Koopman, Sox9 binds
DNA, activates transcription, and coexpresses with type II collagen during chondrogenesis in the mouse, Dev. Biol. 183 (1997) 108-121.

[18] Q. Zhao, H. Eberspaecher, V. Lefebvre, B. de Crombrugghe, Parallel expression of Sox9 and Col2al in cells undergoing chondrogenesis, Dev. Dyn. 209 (1997) 377-386.

[19] H. Akiyama, M.C. Chaboissier, J.F. Martin, A. Schedl, B. de Crombrugghe, The transcription factor Sox 9 has essential roles in successive steps of the chondrocyte differentiation pathway and is required for expression of Sox 5 and Sox6, Genes Dev. 16 (2002) 2813-2828.

[20] K. Klaushofer, F. Varga, H. Glantschnig, N. Fratzl-Zelman, E. Czerwenka, H.J. Leis, K. Koller, M. Peterlik, The regulatory role of thyroid hormones in bone cell growth and differentiation, J. Nutr. 125 (1995) 1996-2003.

[21] H.H. Samuels, F. Stanley, J. Casanova, Depletion of L-3,5,3triiodothyronine and $\mathrm{L}$-thyroxine in euthyroid calf serum for use in cell culture studies of the action of thyroid hormone, Endocrinology 105 (1979) 80-85.

[22] D.L. St. Germain, V.A. Galton, The deiodinase family of selenoproteins, Thyroid 7 (1997) 655-668.

[23] R.L. Vinall, S.H. Lo, A.H. Reddi, Regulation of articular chondrocyte phenotype by bone morphogenetic protein 7 , interleukin 1 , and cellular context is dependent on the cytoskeleton, Exp. Cell Res. 272 (2002) 32-44. 